Case Reports in
Gastroenterology
Case Rep Gastroenterol 2021;15:395-399

DOI: 10.1159/000511748

Published online: March 18, 2021
(C) 2021 The Author(s)

Published by S. Karger AG, Basel www.karger.com/crg

This article is licensed under the Creative Commons Attribution-NonCommercial 4.0 International License (CC BY-NC) (http://www.karger.com/Services/OpenAccessLicense). Usage and distribution for commercial purposes requires written permission.

\title{
Non-Steroidal Anti-Inflammatory Drugs: A Rare Cause of Colonic Mass
}

\author{
Ahmed Baiomi ${ }^{a, b} \quad$ Hafsa Abbas ${ }^{a, b}$ Shehriyar Mehershahi ${ }^{a, b}$ \\ Myrta Daniel ${ }^{a, b}$ \\ aDepartment of Medicine, BronxCare Health System, Bronx, NY, USA; 'bivision of \\ Gastroenterology, BronxCare Health System, Bronx, NY, USA
}

\section{Keywords}

NSAID $\cdot$ Colon mass $\cdot$ NSAID colopathy $\cdot$ Adverse effects of NSAID $\cdot$ Abdominal mass

\begin{abstract}
NSAIDs (non-steroidal anti-inflammatory drugs) are one of the most used medications worldwide. Every day they are used by more than 30 million Americans. Here, we report a rare and interesting case of a 63-year-old woman with a history of NSAID use who presented to our emergency room with lower abdominal pain. Computed tomography (CT) scan of the abdomen with intravenous contrast revealed focal mucosal thickening in the cecum which was highly suspicious for colonic malignancy. She had a colonoscopy which showed two masses and ulcers in the right colon, pathology was negative for malignancy and showed inflammation consistent with NSAID colopathy.

(c) 2021 The Author(s) Published by S. Karger AG, Basel
\end{abstract}

\section{Introduction}

NSAIDs (non-steroidal anti-inflammatory drugs) use is associated with several adverse effects involving the gastrointestinal tract. NSAID-induced complications involving the stomach and duodenum are well described in the medical literature and are frequently encountered by physicians. In an attempt to decrease gastroduodenal side effects, the use of entericcoated, sustained-release, or slow-release NSAID may have shifted the damage to the distal

\begin{tabular}{ll}
\hline & Ahmed Baiomi \\
Division of Gastroenterology \\
Department of Medicine, Bronxcare Health System \\
Bronx, NY 10457 (USA) \\
ahmed251281@yahoo.com
\end{tabular}




\section{Case Reports in Gastroenterology}

Case Rep Gastroenterol 2021;15:395-399

DOI: $10.1159 / 000511748$

c) 2021 The Author(s). Published by S. Karger AG, Basel www.karger.com/crg

Baiomi et al.: Non-Steroidal Anti-Inflammatory Drugs: A Rare Cause of Colonic Mass

small intestine and colon. NSAID causes direct mucosal injury by many mechanisms including interfering with the protective effect of prostaglandins.

They are reported to cause erosions, ulcers, hemorrhage, perforations, strictures and the complications of diverticulosis, in the small and large intestine. There is a wide variety of clinical presentations of NSAID-associated gastrointestinal damage ranging from no symptoms to iron deficiency anemia, abdominal pain, nausea, vomiting, or gastrointestinal bleeding. Here, we report a case of NSAID-induced colopathy mimicking a colonic mass $[1,2]$.

\section{Case Presentation}

A 63-year-old woman presented to the emergency room with lower abdominal pain associated with nausea and vomiting for 3 days. She described the pain as dull, involving the right lower quadrant, non-radiating and constant. She also reported multiple episodes of nonbloody and nonbilious vomiting. Her prior medical problems included osteoarthritis requiring right-sided total knee replacement 5 years prior to this episode. She had been taking ibuprofen $400 \mathrm{mg}$ for knee pain on as needed basis for the past 8 years. She had no family history of inflammatory bowel disease, colon cancer or any other GI-related disorder. She denied smoking, using alcohol and she reported no illicit drug use. She did not have any known drug allergies.

On initial examination in the emergency department, she was afebrile, hemodynamically stable and was not in any distress. Physical examination, including the abdominal examination, was unremarkable. Her laboratory investigations did not reveal any leukocytosis, but CRP was elevated to $55 \mathrm{mg} / \mathrm{L}$. Computed tomography (CT) of the abdomen with intravenous contrast (Fig. 1) showed focal mucosal thickening in the cecum which was highly suspicious for colonic malignancy. Subsequently, the patient underwent a colonoscopy which showed a frond-like/villous, infiltrative, ulcerated, large partially obstructing mass in the ascending colon in close proximity to the cecum (about $4 \mathrm{~cm}$ from the cecum) (Fig. 2) and a large, ulcerated mass in the cecum. Biopsy samples were taken from both masses and pathology showed fragments of colonic mucosa with focal minimal hyperplastic changes, ulceration, mild acute and chronic inflammation and no malignancy. She was evaluated by both surgery and oncology and gastroenterology recommended to repeat colonoscopy with biopsy, but she refused and proceeded with right hemicolectomy, due to a suspicion of colonic malignancy in view of a colonic mass. Examination of the specimen after surgery showed an ascending colon mass measuring $3.2 \times 2.5 \mathrm{~cm}$ and a cecum mass measuring $2 \mathrm{~cm} \times 1.5 \mathrm{~cm}$. Histopathology showed fibrinosuppurative exudate, granulation tissue and fibrosis with reactive changes. There was no evidence of malignant inflammatory bowel disease, ischemic colitis, granuloma, viral inclusion body or parasite. In view of isolated colonic ulcers in the setting of NSAID use, NSAIDinduced colopathy was suggested. The patient was instructed to avoid NSAIDs.

\section{Discussion}

NSAIDs are widely used to treat pain and fever associated with a wide range of medical conditions such as arthritis, menstrual cramps, headaches, colds, and influenza. They are available by prescription and over the counter and are generally well-tolerated. The most common side effects are dyspepsia, nausea, and vomiting. Rarely, serious side effects, such as

\section{Karger'=}




\section{Case Reports in Gastroenterology}

\begin{tabular}{l|l}
\hline Case Rep Gastroenterol 2021;15:395-399 \\
\hline DOI: 10.1159/000511748 & $\begin{array}{l}\text { ○ 2021 The Author(s). Published by S. Karger AG, Basel } \\
\text { www.karger.com/crg }\end{array}$ \\
\hline
\end{tabular}

Baiomi et al.: Non-Steroidal Anti-Inflammatory Drugs: A Rare Cause of Colonic Mass

gastrointestinal ulceration or bleeding, may occur, which are more likely to be associated with high doses and prolonged use. The toxicity of NSAIDs is not limited to the gastroduodenum, but it also involves the small and large intestine. The typical colonic mucosal injuries that occur are ulcerations, exacerbation of inflammatory bowel disease, NSAID-induced diverticular bleeding, and colonic strictures [1,3].

Symptoms related to NSAID colopathy are diverse: some patients have no symptoms, others present with iron deficiency anemia and/or frank bleeding from ulcers; anemia, hypoalbuminemia, or malabsorption from enteropathy, intermittent or complete bowel obstruction from broad-based or diaphragm-like strictures, watery or bloody diarrhea from colitis, and acute abdomen from perforation $[4,5]$.

Findings on capsule endoscopy [6], balloon-assisted enteroscopy [7], and/or colonoscopy may lend support to the diagnosis of NSAID-induced injury, although there is nothing endoscopically specific about NSAID-induced erosions, ulcers, or colitis. Histology is also nonspecific. The differential diagnosis should thus include infectious etiologies (e.g., Campylobacter, Yersinia, cytomegalovirus, TB), irritable bowel disease, ischemia, radiation enteritis, vasculitides, and other drugs (e.g., potassium chloride tablets) [8-10].

NSAID-induced colopathy is diagnosed based on the following criteria: (1) presence of colonic lesions confirmed by colonoscopy; (2) administration of NSAIDs before colitis; (3) absence of other diseases, such as inflammatory bowel disease, amyloidosis, infectious colitis, and ischemic colitis; and (4) confirmation of improved ulcers by repeated colonoscopy after discontinuation of NSAIDs $[11,12]$.

Cessation of NSAID use will result in regression of the inflammation and healing of erosions and ulcers. However, strictures often do not regress, and sometimes need to be treated with balloon dilatation or even surgical regression [13].

In conclusion, NSAIDs are well known for their ability to cause gastrointestinal side effects mostly in the upper GI tract. The effect of NSAIDs on the small intestine and colon is less common, but reported. Awareness of the clinical, endoscopic, and histopathologic aspects of NSAID-induced colopathy as well as detailed medical drug history is therefore necessary to diagnose this clinical condition which may closely mimic colonic malignancy so that unnecessary surgical intervention can be avoided.

\section{Statement of Ethics}

This study was performed in accordance with the ethical standards of the Committee on Human Experimentation of our institution and the tenets of the World Medical Association Declaration of Helsinki. The patient provided informed consent for publication of this report and the accompanying images.

\section{Conflict of Interest Statement}

The authors declare that they have no conflicts of interest.

\section{Karger' $=$}




\section{Case Reports in Gastroenterology}

\section{Funding Sources}

No funding was received.

\section{Author Contributions}

Ahmed Baiomi wrote the initial manuscript. Hafsa Abbas and Shehriyar Mehershahi reviewed the images and manuscript. Myrta Daniel critically reviewed and modified the manuscript.

\section{References}

1 Geramizadeh B, Taghavi A, Banan B. Clinical, endoscopic and pathologic spectrum of non-steroidal antiinflammatory drug-induced colitis. Indian J Gastroenterol. 2009 Jul-Aug;28(4):150-3.

2 Tanner AR, Raghunath AS. Colonic inflammation and nonsteroidal anti-inflammatory drug administration. An assessment of the frequency of the problem. Digestion. 1988;41(2):116-20.

3 Mokhtare M, Valizadeh SM, Emadian O. Lower Gastrointestinal Bleeding due to Non-Steroid AntiInflammatory Drug-Induced Colopathy Case Report and Literature Review. Middle East J Dig Dis. 2013 Apr;5(2):107-11.

4 Bjarnason I, Hayllar J, MacPherson AJ, Russell AS. Side effects of nonsteroidal anti-inflammatory drugs on the small and large intestine in humans. Gastroenterology. 1993 Jun;104(6):1832-47.

5 Newton JL, Johns CE, May FE. Review article: the ageing bowel and intolerance to aspirin. Aliment Pharmacol Ther. 2004 Jan;19(1):39-45.

6 Graham DY, Opekun AR, Willingham FF, Qureshi WA. Visible small-intestinal mucosal injury in chronic NSAID users. Clin Gastroenterol Hepatol. 2005 Jan;3(1):55-9.

7 Hayashi Y, Yamamoto H, Kita H, Sunada K, Sato H, Yano T, et al. Non-steroidal anti-inflammatory druginduced small bowel injuries identified by double-balloon endoscopy. World J Gastroenterol. 2005 Aug;11(31):4861-4.

8 Kwo PY, Tremaine WJ. Nonsteroidal anti-inflammatory drug-induced enteropathy: case discussion and review of the literature. Mayo Clin Proc. 1995 Jan;70(1):55-61.

9 Kaufman HL, Fischer AH, Carroll M, Becker JM. Colonic ulceration associated with nonsteroidal antiinflammatory drugs. Report of three cases. Dis Colon Rectum. 1996 Jun;39(6):705-10.

10 Lengeling RW, Mitros FA, Brennan JA, Schulze KS. Ulcerative ileitis encountered at ileo-colonoscopy: likely role of nonsteroidal agents. Clin Gastroenterol Hepatol. 2003 May;1(3):160-9.

11 Ballinger A. Adverse effects of nonsteroidal anti-inflammatory drugs on the colon. Curr Gastroenterol Rep. 2008 Oct;10(5):485-9.

12 Kurahara K, Matsumoto T, Iida M, Honda K, Yao T, Fujishima M. Clinical and endoscopic features of nonsteroidal anti-inflammatory drug-induced colonic ulcerations. Am J Gastroenterol. 2001 Feb;96(2):47380.

13 Van Weyenberg SJ, de Boer NK. Nonsteroidal Anti-Inflammatory Drug Associated Colopathy. Video Journal and Encyclopedia of GI Endoscopy. 2013;1(2):386-87. https://doi.org/10.1016/S2212-0971(13)70171-7. 
Case Reports in Gastroenterology
Case Rep Gastroenterol 2021;15:395-399

DOI: $10.1159 / 000511748$

c) 2021 The Author(s). Published by S. Karger AG, Basel www.karger.com/crg

Baiomi et al.: Non-Steroidal Anti-Inflammatory Drugs: A Rare Cause of Colonic Mass

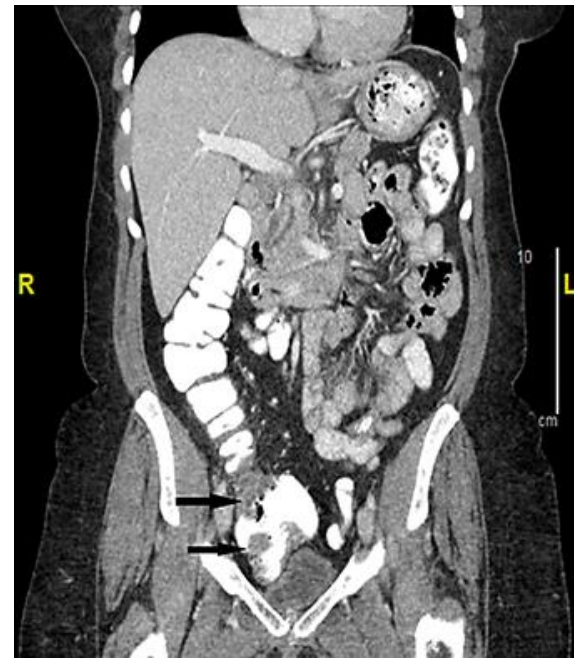

Fig. 1. Computed tomography image of the abdomen with oral and intravenous contrast (coronal view), arrow pointing to thickened cecum.

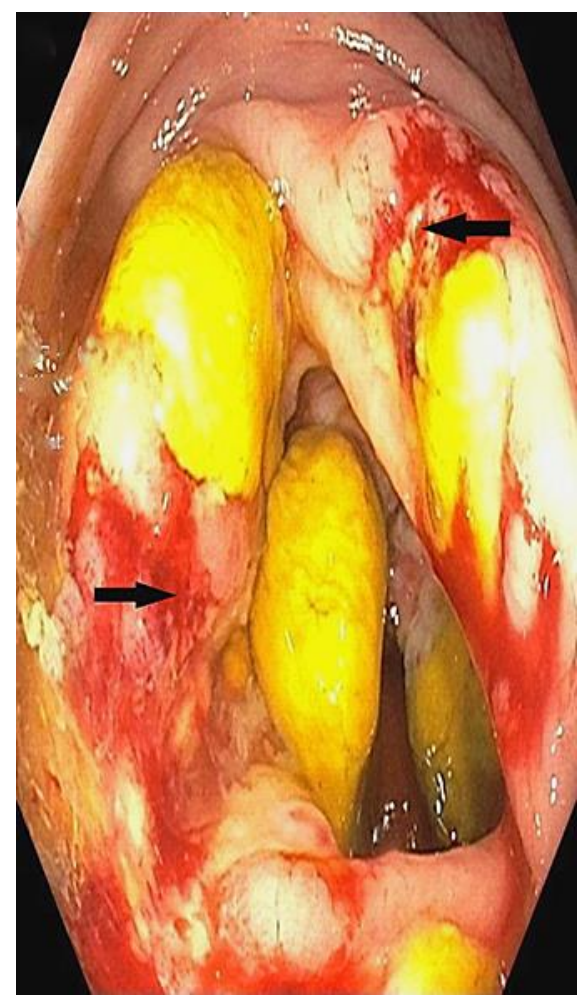

Fig. 2. Colonoscopy examination: colonoscopy image with arrow pointing to an ulcerated, large partially obstructing mass in the ascending colon.

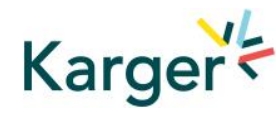

